Original article

\title{
Differences in bite force between dolichofacial and brachyfacial individuals: Side of mastication, gender, weight and height
}

\author{
Paulo Roberto Quiudini Jr. MSci in TMD and Orofacial Pain Clinic ${ }^{a}$, \\ Daniel Humberto Pozza ${ }^{b, *}$, Ary dos Santos Pinto ${ }^{c}$, \\ Mauricio Ferraz de Arruda ${ }^{d}$, Antonio Sergio Guimarães ${ }^{a}$ \\ ${ }^{a}$ Department of TMD and Orofacial Pain, Dental Research Institute, Sao Leopoldo Mandic, Brazil \\ ${ }^{\mathrm{b}}$ Departamento de Biologia Experimental, Faculdade de Medicina/Faculdade de Ciências da Nutrição e Alimentação da \\ Universidade do Porto and I3s, Porto, Portugal \\ ${ }^{c}$ Children's Clinic Department, Araraquara Dental School of Universidade Estadual Paulista (UNESP), Brazil \\ ${ }^{d}$ Mestrado em Bases Gerais da Cirurgia FMB-UNESP, Departamento de Ciências da Saúde do IMES-Instituto \\ Municipal de Ensino Superior de Catanduva, Brazil
}

\section{A R T I C L E I N F O}

Article history:

Received 26 March 2015

Received in revised form

26 July 2016

Accepted 23 October 2016

Available online 17 November 2016

Keywords:

Bite force

Facial type

Facial pattern

\begin{abstract}
A B S T R A C T
Purpose: Due to the bite force importance in functionality of the masticatory system, this study aimed to characterize it in dolichofacial and brachyfacial individuals.

Methods: A sample comprised by 190 patients was divided into two groups: 90 severe dolichofacial, and 100 severe brachyfacial individuals classified according to the VERT index and the face height ratio (Jarabak quotient). Bite force was measured by using an adjusted digital dynamometer and proper methodology.

Results: The sample met the parametric assumptions and presented statistical significance when right and left sides of dolichofacial and brachyfacial individuals were compared. However, within the same group, no differences between the left and right sides were found. Generally, bite force was higher for male, left masticator, age between 41-50 years, weighing over $100 \mathrm{~kg}$ and between 1.81 and $1.90 \mathrm{~m}$ tall.

Conclusions: Based on the results of this cross-sectional study, it was possible to conclude that the bite force in severe brachyfacial individuals was significantly higher than in severe dolichofacial individuals, being influenced by gender, weight and height.
\end{abstract}

(c) 2016 Japan Prosthodontic Society. Published by Elsevier Ltd. All rights reserved.

\footnotetext{
* Corresponding author at: Departamento de Biologia Experimental, Faculdade de Medicina, Al. Hernâni Monteiro 4200-319, Porto, Portugal. E-mail address: dhpozza@gmail.com (D.H. Pozza).
}

http://dx.doi.org/10.1016/j.jpor.2016.10.003

1883-1958/@ 2016 Japan Prosthodontic Society. Published by Elsevier Ltd. All rights reserved. 


\section{Introduction}

Bite force (BF) is an indicator of the functional status of the masticatory system [1], and is related to the facial morphology, occlusion, neuromuscular mechanism and variables such as gender, age and body type [2-5]. The BF produced during clenching in maximum voluntary contraction is the result of the action of at least six jaw elevator muscles and is related to the function of the masticatory system $[3,6,7]$. The variance in BF may be explained by differences in muscle size and thickness, sarcomere length-tension relation, craniofacial morphology, vertical jaw relation, facial height and inclination, shape and length of the jaw, and it is influenced by the dental region assessed as well as occlusion type [8,9]. It is also known that maximum bilateral BF is significantly lower than the maximum unilateral $\mathrm{BF}$, and differences between the left and right sides should not exist. Furthermore, unilateral clenching leads to different response of the temporal muscle when compared to the masseter muscle [10].

Facial typology is related to dental occlusion, facial harmony, orofacial muscles, as well as the shape and configuration of the craniofacial structures, influencing chewing, swallowing, breathing and speech. There are countless facial typology classifications in the literature, among which Tweed [11], that assessed the vertical dysplasia of the face using the Frankfort Mandibular-Plane Angle (FMA); Jarabak [12], who categorized facial morphology based on three different patterns, defined by the facial height ratio (FHR) or Jarabak quotient [12]; and Ricketts [13], based on the VERT index, using five measurements (mandibular plan, facial axis, anterior lower facial height, mandibular arch and facial depth) to determine ideal values for a harmonic face, according to the individuals' age. The results of facial pattern could be summarized in: severe dolichofacial (below -2.0), dolichofacial (below -0.5), mesofacial (between -0.49 and +0.49 ), brachyfacial (above +0.5 ) and severe brachyfacial (above +1.0). Taking into account the importance of the influence of the musculature on craniofacial development, as well as to establish a baseline for future comparisons, the objective of this cross-sectional study was to assess bite force according to facial typology and other specific variables such as gender, age, weight and height.

\section{Materials and methods}

During the years of 2012 and 2013 a total 4033 patients of the Orthodontic Clinic of São Leopoldo Mandic Faculty (Campinas, Brazil) were screened and 190 consenting individuals met the inclusion criteria of this study: general good health, good oral hygiene, first four permanent molars having made their eruption, regardless of age, being classified either as DL or BR based on the VERT index (Ricketts) and the FHR (Jarabak quotient). The exclusion criteria comprised individuals that were in active orthodontic treatment and/or possessed temporomandibular disorders symptoms [14]. Patients were allocated into two groups; 90 severe dolichofacial individuals (Vert $<$ or $=-2$; DL), and 100 severe brachyfacial individuals (Vert $>$ or $=+1$; BR). Sample size was defined based on previous studies in the literature [15-17]. The study was approved by the local Ethical and Research Board, protocol number 2012/0160, and all participants agreed to sign an informed consent.

$\mathrm{BF}$ was measured with the use of a digital dynamometer (IDDK-Kratos Equipamentos Industriais Ltda, Cotia, Brazil) adapted to the oral conditions. BF measurements were conducted with the individuals in a sitting position, corresponding to the meatus-orbital plane, parallel to the ground in a comfortable chair, with their arms outstretched alongside their bodies and hands placed open on their thighs. Before any measurements were recorded, volunteers received detailed instructions, and tests were performed with the volunteers biting into the equipment to ensure the reliability of the procedure [18].

The device's biting pads were placed on the occlusal face between the upper and lower first molars, right and left alternately. The volunteers were then asked to bite into the device with maximum force. Three BF peak measurements (Newton-N) were collected from each side of the mouth with an interval of $10 \mathrm{~s}$ between them. The highest BF measured on each side was registered. New measurements were conducted one month later in all volunteers, and the highest $\mathrm{BF}$ registered in the measurements on each side was considered for this study (Fig. 1).

Since the sample met the parametric analysis assumptions (Bartlett and D'Agostino-Pearson tests), errors with normal distribution, and homogeneity of variances, the data were compared with the use of appropriated statistical tests for each circumstance. Age, weight, height and BF presented normal distribution and were compared by using two-way ANOVA, followed by Tukey post hoc. Chi-square test was used to compare gender proportions. The intraclass correlation coefficient (ICC) was applied to ensure reliability regarding the agreement rate measurement of $\mathrm{BF}$ (left and right) taken at six periods according to the facial type. Pearson correlation coefficient was used whenever possible to verify the association between BF and remaining variables. Facial type dependency in relation to the remaining variables was observed through simple logistic regression (Backward StepwiseWald). Level of significance of 0.05 was used (BioEstat 5.0, GraphPad Prism 6.0 and SPSS 21.0).

\section{Results}

Among the 190 patients considered in the analysis, 100 were classified as severe brachyfacial individuals (BR, short face) and 90 as severe dolichofacial individuals (DL, long face). The sample was composed by 93 females (48.9\%), and patients' mean age, weight and height were 23.9 \pm 9.2years, 68.5 $\pm 16.6 \mathrm{~kg}$, and $1.67 \pm 0.1 \mathrm{~m}$, respectively. All individuals were equally paired between the two test groups according to age $(23.3 \pm 8.7$ for DL and $24.5 \pm 9.6$ for BR, $\mathrm{p}=0.3645)$ and height (the same height for both groups, $p=0.7490)$. Despite higher for $B R$ (70.4 \pm 17.6$)$ than for DL $(66.4 \pm 15.2, p=0.0987)$, the overall weight was not quite significantly between groups.

Concerning the masticatory side, $50 \%$ of BR patients possessed bilateral bite preference; $33.3 \%$ bilateral, predominantly right; $13.7 \%$ bilateral, predominantly left; and $2.9 \%$ only bite on the right side. Among DL individuals, $44.0 \%$ possessed 


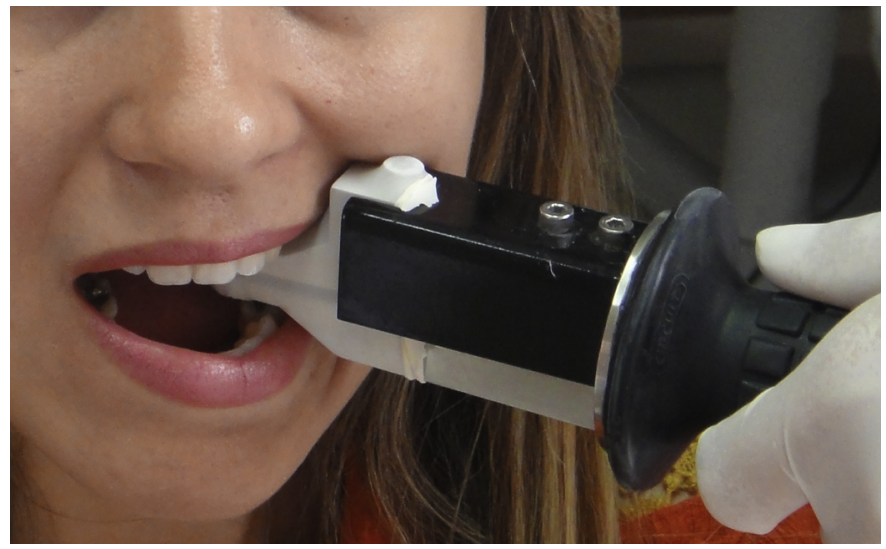

Fig. 1 - Representative image of the dynamometer during the BF values acquisition.

\begin{tabular}{|c|c|c|c|c|c|c|}
\hline & \multicolumn{2}{|c|}{$\mathrm{BR}(\mathrm{n}=100)$} & \multicolumn{2}{|c|}{$\mathrm{DL}(\mathrm{n}=90)$} & \multicolumn{2}{|c|}{$\mathrm{p}$} \\
\hline & Female & Male & Female & Male & Between groups & Between genders \\
\hline $\mathrm{N}(\%)$ & $50(50 \%)$ & $50(50 \%)$ & $43(47.8 \%)$ & $47(52.2 \%)$ & $0.8724^{\mathrm{CS}}$ & $0.8277^{\mathrm{CS}}$ \\
\hline Age (years) & $23.2( \pm 8.8)$ & $25.8( \pm 10.3)$ & $23.3( \pm 9.2)$ & $23.3( \pm 8.4)$ & 0.3642 TWA & 0.3194 TWA \\
\hline Weight (Kg) & $63.6( \pm 15.9)$ & $77.3( \pm 16.9)$ & $60.6( \pm 13.0)$ & $71.8( \pm 15.3)$ & $0.0847^{\text {TWA }}$ & $<0.000^{\text {TWA }}$ \\
\hline Height $(\mathrm{m})$ right & $1.6( \pm 0.08)$ & $1.7( \pm 0.09)$ & $1.6( \pm 0.07)$ & $1.7( \pm 0.09)$ & $0.3893^{\text {TWA }}$ & $<0.000^{\mathrm{TWA}}$ \\
\hline Right side $\mathrm{BF}(\mathrm{N})$ & $406.6( \pm 136.9)$ & $597.5( \pm 214.8)$ & $368.5( \pm 145.3)$ & $503.6( \pm 193.9)$ & $0.0109^{\text {TWA }}$ & $<0.000^{\text {TWA }}$ \\
\hline Left side $B F(N)$ & $418.5( \pm 143.1)$ & $611.6( \pm 223.7)$ & $376.8( \pm 157.0)$ & $495.9( \pm 198.0)$ & $0.0036^{\text {TWA }}$ & $<0.000^{\text {TWA }}$ \\
\hline Mean BF (N) & $412.6( \pm 131.9)$ & $604.6( \pm 212.7)$ & $372.6( \pm 148.5)$ & $499.7( \pm 189.5)$ & $0.0048^{\text {TWA }}$ & $<0.000^{\mathrm{TWA}}$ \\
\hline
\end{tabular}

Legend: BR—severe brachyfacial patients; DL—severe dolichofacial patients; BF—bite force; N-Newton; CS: Chi-square test; TWA: two-way ANOVA test. Values represented as mean ( \pm standard deviation).

bilateral bite; $33.0 \%$ bilateral, mostly right; $15.0 \%$ bilateral mostly left; $6.0 \%$ only bite on the right side; and $2.0 \%$ only bite on the left side. However, within the same group, no differences between the left and right sides were found in DL $(p=0.9991)$ or BR $(p=0.6576)$. The intraclass correlation coefficient (ICC) that evaluated the bite force measurements was considered excellent for DL (left side: $\mathrm{ICC}=0.92, \mathrm{p}<0.0001$, right side: ICC $=0.89, \mathrm{p}<0.0001$ ) and for $\mathrm{BR}$ (left side: $\mathrm{ICC}=0.93$, $\mathrm{p}<0.0001$, right side: $\mathrm{ICC}=0.91, \mathrm{p}<0.0001$ ) individuals.

The BF in the overall population studied was significantly higher for BR individuals $(508.5 \pm 206.5 \mathrm{~N})$ than DL individuals $(437.7 \pm 185.6 \mathrm{~N}, \mathrm{p}<0.001)$. This difference remained when $\mathrm{DL}$ and $B R$ were compared on the left $(p=0.0036)$ and the right sides $(p=0.0109)$, as demonstrated in Table 1.

When individuals of different genders were compared, males presented higher values for weight and height $(p<0.0001)$, and BF was significantly higher for males than females, both in DL and BR $(p<0.0001)$ patients, regardless of the facial type or bite side (Table 1). Although DL and BR women did not present significative differences in $B F$ for mean $(p=0.6891)$, right $(p=0.7273)$ and left $(p=0.6960)$ sides, $B R$ men had height mean $(p=0.0180)$, right $(p=0.0408)$ and left $(p=0.0120)$ bite forces than DL men.

Taking into account participants' age, it was observed that maximum bite force found for BR patients increased steadily according to the aging. On the other hand, for DL patients maximum bite force rose until 21-30 years, reducing gradually from 31 years. (Fig. 2). The multiple comparison analysis

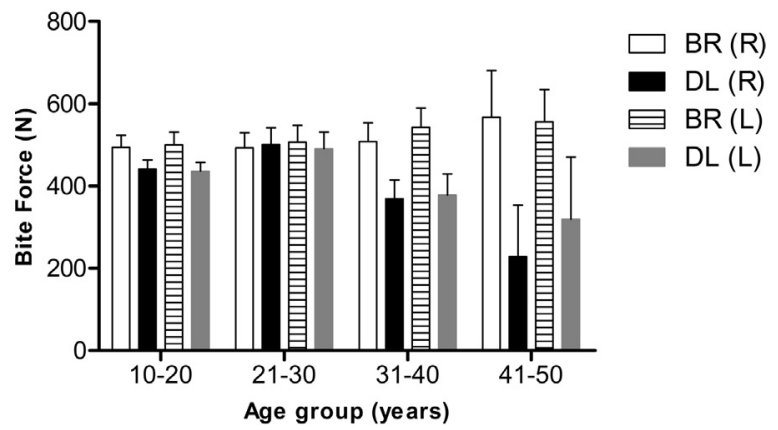

Fig. 2 - Mean bite force on the right and left sides of dolichofacial and brachyfacial individuals according to their age. Legend: BR-severe brachyfacial patients; DL-severe dolichofacial patients; BF-bite force; N-Newton; R-right; L-left.

showed no correlations among BF and age for BR $(r=0.044$ for right and $r=0.065$ for left side) or DL individuals $(r=-0.091$ for right and $r=-0.071$ for left side).

A direct relationship between higher weight and higher bite force was observed on both sides both for BR and DL individuals (Fig. 3). The multiple comparison analysis showed a weak correlation among BF and weight for $B R(r=0.370$ for right and $r=0.358$ for left side) and a moderate correlation among BF and weight for DL individuals $(r=0.454$ for right and $r=0.407$ for left side). 


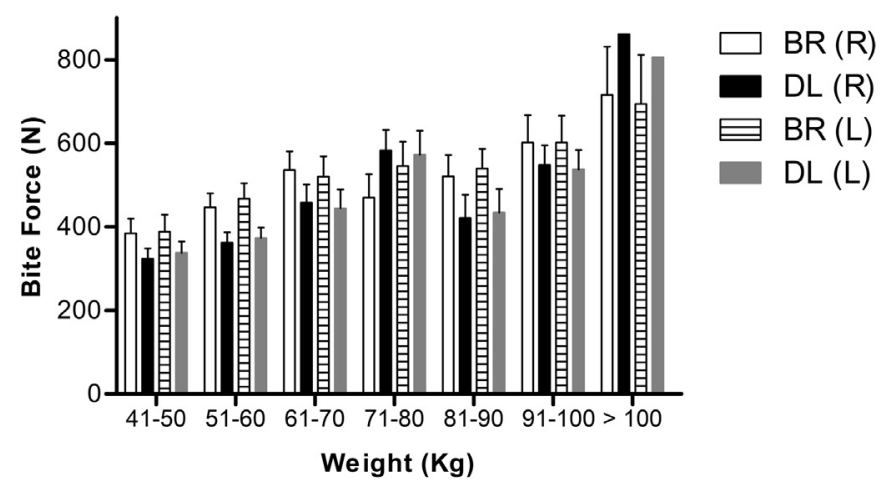

Fig. 3-Mean bite force on the right and left sides of dolichofacial and brachyfacial individuals according to their weight. Legend: BR-severe brachyfacial patients; DL-severe dolichofacial patients; BF-bite force; N-Newton; R-right; L-left.

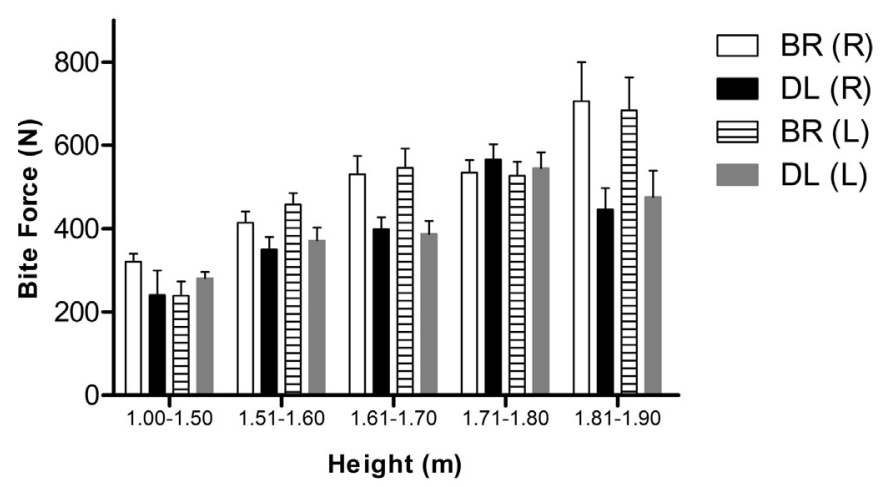

Fig. 4-Mean bite force on the right and left sides of dolichofacial and brachyfacial individuals according to their height. Legend: BR-severe brachyfacial patients; DL-severe dolichofacial patients; BF-bite force; N-Newton; R-right; L-left.

Table 2 - Adjusted model of logistic regression to facial morphology ( $\mathrm{DL}=1$ and $\mathrm{BR}=0$ ) as dependent variable.

\begin{tabular}{llllllcr} 
& Beta & SE & Wald & DF & p & Exp(B) & CI95\% \\
\hline Gender & 0.29 & 0.369 & 0.598 & 1 & 0.4394 & 1.33 & $0.64-2.74$ \\
Weight & -0.026 & 0.012 & 4.25 & 1 & 0.0393 & 0.98 & $0.95-1.00$ \\
Height & 4.73 & 2.18 & 4.71 & 1 & 0.0300 & 112.7 & $1.58-8056.2$ \\
Mean BF & -0.0022 & 0.00093 & 5.84 & 1 & 0.0156 & 0.998 & $0.996-0.999$ \\
Constant & -5.36 & 3.19 & 2.82 & 1 & 0.0930 & 0.0047 & \\
\hline
\end{tabular}

Legend: SE—standard error; DF—degrees of freedom; CI—confidence interval; Exp(B)—beta coefficient; BF—bite force.

A trend to increased BF with increased height was also observed in BR patients in general, and up to $1.80 \mathrm{~m}$ in $\mathrm{DL}$ patients, a point from which BF started to decrease (Fig. 4). The multiple comparison analysis showed a weak correlation among BF and height for $B R(r=0.357$ for right and $r=0.288$ for left side) and a moderate correlation among BF and height for DL individuals $(r=0.402$ for right and $r=0.346$ for left side).

Additionally, the correlations between age and height were weak for both groups ( $r=0.224$ for $B R$ and $r=0.269$ for DL individuals) and also weak for BR when age and weight were compared $(r=0.388)$. However, a moderate correlation between age and weight was found for DL individuals $(r=0.438)$. Finally, a strong correlation between height and weight were found for $B R(r=0.635)$ and for DL individuals $(r=0.684)$.
A logistic regression was performed taking into consideration facial morphology (dependent variable: $\mathrm{DL}=1$ and $\mathrm{BR}=0$ ) and remaining variables. The adjusted model presented statistical significance (Chi-square $=14.74, p=0.0209$ ), being Nagelkerke $R^{2}=0.0991$. Furtheremore, Hosner and Lemeshow test showed that the model is appropriate (Chi-square $=16.52$, $\mathrm{p}=0.0355)$ with the following regression logo: facial morphology $=-5.36+(0.29 \times$ gender $)-(0.026 \times$ wheight $)+(4.73 \times$ heigh $)$ $-(0.0022 \times$ mean BF $)$. Considering males $=1$ and females $=0$, results higher than 0.5 indicated DL and results lower than 0.5 indicated BR individuals. Consequently, there was a dependency between facial morphology and gender, weight, height and mean $B F$, but not age $(p=0.6765)$. The predictability of the model was $65.3 \%$, being $70 \%$ for classifying BR individuals and $60 \%$ for DL (Table 2). 
Rare exceptions to the rule were observed, in which DL individuals presented higher values than BR individuals: Above $71-80 \mathrm{~kg}$ and $101 \mathrm{~kg}$ (Fig. 3); and 1.71-1.80 m tall (Fig. 4). However, no statistical significance was found for these exceptions. Thus, in general, the individual that presented the highest BF belonged to the BR group, was a left masticator, male, age between 41-50 years, weighing over $100 \mathrm{~kg}$ and between 1.81 and $1.90 \mathrm{~m}$ tall. On the other hand, the individual with the lowest BF belonged to DL group, was a right masticator, female, weighing less than $50 \mathrm{~kg}$, age between 10-20 years and between 1.00 and $1.50 \mathrm{~m}$ tall.

\section{Discussion}

By using different facial classification methods to reduce possible distortions and superposition of anatomic structures, adequate methodology to ensure that the buccal opening did not interfere with the force used, avoiding muscle stretch and the exaggerated displacement of the condyles [19,20]; it was possible to determine that the mean of maximum bite force (BF) in severe brachyfacial individuals (BR) was significantly higher than in severe dolichofacial individuals (DL), and that BF was influenced by the individuals' gender, age, weight and height.

$\mathrm{A}$ wide range of maximum $\mathrm{BF}$ and correlations with cephalometric standards have already been reported in the literature. The differences among studies are possibly related to differences in instrument design, methodologies, uni or bilateral measurements, jaw opening, individual tolerance, pain threshold, anxiety, mental attitude, head posture, and others $[15,19,21-27]$. In this study, BF was assessed in the posterior region [28], alternating bilaterally, with a plastic pads digital dynamometer. Individuals may feel reluctant to effectively bite into the metal pads, fearing dental damage or pain. In this study, the pliable pads did not discouraged volunteers to use maximum force when biting; furthermore, it was designed in small size to avoid distracting the condyles excessively. Moreover, participants were previously trained with the equipment before the BF data collection in order to improve the dynamics of response capacity and transducer precision $[24,25,29]$. Some authors claim that laminar pressure sensors, thin force resistors and strain gages promote only small alterations in the occlusion, but need expensive specific equipment and professional qualification for the calculations $[19,30,31]$.

Maximum BF measurements are dependent on the motivation and cooperation of individuals. Their concern with possible damage, pain and discomfort in their teeth and stomatognatic system, as well as psychological factors, may negatively influence in BF measurements. Pain limits maximum $B F$ due to the reflex mechanisms and prevents accurate measurements. Nonetheless, this factor may also indicate the real functional capacity of the patient and, therefore, provides useful information for control treatment [14,32-35]. In this study, individuals that were in active orthodontic treatment and/or possessed temporomandibular disorders symptoms and/or orofacial pain were excluded to avoid measurement bias. Moreover, subjects were paired whenever possible (by age and height). Pairing by weight, however, was not possible since BR individuals demonstrated a tendency for increased weight, consistent with the short faces, while DL individuals for lower weight, consistent with long faces.

In order to ensure the measurement reliability individuals were requested to bite the device in the right and left first molars alternately, using their maximum force, at least 3 times per side. Furthermore, to ensure the consistence of the results, new measurements were conducted one month later in all volunteers and similar results were found, with no statistical differences and excellent ICC concordance. Among minimum and mean, the maximum BF was considered for this study since it is the most reliable measurement, because it is the limit that someone can reach, thus easy for the patients to understand. The other measurements (average or minimum force) are not so accurate since it is harder to state, as well as to understand, how much it should be. Finally, the average of maximum BF was not used in this study because it is lower than the real maximum BF reached.

The results obtained in this study are in agreement with the literature $[8,15,24,25,36,37]$, since facial type influenced in muscular force, with BR individuals presenting the highest results for BF. Other factors, apart from facial morphology, such as the overall physical structure, gender, status of the dentition, and age can also influence BF $[38,39]$. As a result of anatomical characteristics, males demonstrated higher $\mathrm{BF}$ than females [33,40-45], regardless of the facial type or bite side. According to the results found in this study, it was observed that even DL males showed higher mean of BF than BR females. Braun et al. [23] observed that the correlation between maximum $\mathrm{BF}$ and gender was not evident up to 18 years of age. In this study, however, BF was always significantly higher for males than for females, regardless of age, even in younger individuals aged less than 18 years.

In this cross-sectional study an ascending BF curve was found up constantly to BR individuals, but not to DL subjects were the peak happened at 21-30 years, decreasing with the aging and corroborating with the results founded by previous studies [41,42]. This reduction in BF was sharpest and inverse to older age. Previous authors observed that maximum BF did not correlate well with age $[3,16,23,25]$. However, in those studies, samples were composed only by adults aged 26-41 years.

The concept that people with larger and heavier bodies demonstrate higher BF was not confirmed by Braun et al. [25] The best correlation found was related to weight, indicating that only $16 \%$ of BF variability was accounted by participants' weight. This result is in agreement with a previous study performed by Linderholm \& Wennstrom in the 70s [46]. However, in the present studied population, weight was found to have a strong correlation with $\mathrm{BF}$, as it steadily increased according to individuals' weight, regardless of facial type or bite side.

It is interesting to note that although BR individuals, given their body characteristics, did not generally surpass $1.90 \mathrm{~m}$ in height, BF progressively increased with increased height. On the other hand, DL individual's BF increased up to $1.71-1.80 \mathrm{~m}$, from which it inversely reduced with the increased height. Different from our study, Braun et al. [25] reported poor 
correlation between height and $\mathrm{BF}$, but it is important to mention that their sample was much smaller than the one used in the present study, which restricts comparisons.

\section{Conclusion}

Finally, based on the results obtained in this study, it was possible to conclude that maximum BF in severe brachyfacial individuals is generally higher than in severe dolichofacial individuals.

\section{R E F E R E N C E S}

[1] Hagberg C. Assessment of bite force: a review. J Craniomandib Disord 1987;1:162-9.

[2] Bakke M, Tuxen A, Vilmann P, Jensen BR, Vilmann A, Toft M. Ultrasound image of human masseter muscle related to bite force, electromyography, facial morphology, and occlusal factors. Scand J Dent Res 1992;100:164-71.

[3] Shiau YY, Wang JS. The effects of dental condition on hand strength and maximum bite force. Cranio 1993;11:48-54 discussion.

[4] Kiliaridis S, Johansson A, Haraldson T, Omar R, Carlsson GE. Craniofacial morphology, occlusal traits, and bite force in persons with advanced occlusal tooth wear. Am J Orthod Dentofac Orthop 1995;107:286-92.

[5] Raadsheer MC, Kiliaridis S, Van Eijden TM, Van Ginkel FC, Prahl-Andersen B. Masseter muscle thickness in growing individuals and its relation to facial morphology. Arch Oral Biol 1996;41:323-32.

[6] Fontijn-Tekamp FA, Slagter AP, Van Der Bilt A, Van THMA, Witter DJ, Kalk W, et al. Biting and chewing in overdentures, full dentures, and natural dentitions. J Dent Res 2000;79:151924.

[7] Pereira LJ, Gaviao MB, Bonjardim LR, Castelo PM, Andrade Ada S. Ultrasonography and electromyography of masticatory muscles in a group of adolescents with signs and symptoms of TMD. J Clin Pediatr Dent 2006;30:314-9.

[8] Raadsheer MC, van Eijden TM, van Ginkel FC, Prahl-Andersen B. Contribution of jaw muscle size and craniofacial morphology to human bite force magnitude. J Dent Res 1999;78:31-42.

[9] Sonnesen L, Bakke M. Molar bite force in relation to occlusion, craniofacial dimensions, and head posture in pre-orthodontic children. Eur J Orthod 2005;27:58-63.

[10] van der Bilt A, Tekamp A, van der Glas H, Abbink J. Bite force and electromyograpy during maximum unilateral and bilateral clenching. Eur J Oral Sci 2008;116:217-22.

[11] Tweed CH. Was the development of the diagnostic facial triangle as an accurate analysis based on fact or fancy. Am J Orthod 1962;48:823-40.

[12] Jarabak JR. Open bite: skeletal morphology. Fortsch Kieferorthop 1983;44:122-33.

[13] Ricketts RM, Roth RH, Chaconas SJ, Schulhof RJ, Engel GA. Orthodontic diagnosis and planning: their roles in preventive and rehabilitative dentistry. Denver, CO: Rocky Mountain; Orthodontics; 1982.

[14] De Boever JA, Nilner M, Orthlieb JD, Steenks MH. Recommendations by the EACD for examination, diagnosis, and management of patients with temporomandibular disorders and orofacial pain by the general dental practitioner. J Orofac Pain 2008;22:268-78.

[15] Kiliaridis S, Kjellberg H, Wenneberg B, Engstrom C. The relationship between maximal bite force, bite force endurance, and facial morphology during growth. A crosssectional study. Acta Odontol Scand 1993;51:323-31.

[16] Sonnesen L, Bakke M, Solow B. Temporomandibular disorders in relation to craniofacial dimensions, head posture and bite force in children selected for orthodontic treatment. Eur J Orthod 2001;23:179-92.

[17] Abu Alhaija ES, Al Zo'ubi IA, Al Rousan ME, Hammad MM. Maximum occlusal bite forces in Jordanian individuals with different dentofacial vertical skeletal patterns. Eur J Orthod 2010;32:71-7.

[18] Palinkas M, Nassar MS, Cecilio FA, Siessere S, Semprini M, Machado-de-Sousa JP, et al. Age and gender influence on maximal bite force and masticatory muscles thickness. Arch Oral Biol 2010;55:797-802.

[19] Fernandes CP, Glantz PO, Svensson SA, Bergmark A. A novel sensor for bite force determinations. Dent Mater 2003;19:11826.

[20] Castelo PM, Gaviao MB, Pereira LJ, Bonjardim LR. Masticatory muscle thickness, bite force, and occlusal contacts in young children with unilateral posterior crossbite. Eur J Orthod 2007;29:149-56.

[21] Helkimo E, Carlsson GE, Helkimo M. Bite force and state of dentition. Acta Odontol Scand 1977;35:297-303.

[22] van Steenberghe D, de Vries JH. The development of a maximal clenching force between two antagonistic teeth. J Periodontal Res 1978;13:91-7.

[23] Braun S, Hnat WP, Freudenthaler JW, Marcotte MR, Honigle K, Johnson BE. A study of maximum bite force during growth and development. Angle Orthod 1996;66:261-4.

[24] Proffit WR, Fields HW. Occlusal forces in normal- and longface children. J Dent Res 1983;62:571-4.

[25] Braun S, Bantleon HP, Hnat WP, Freudenthaler JW, Marcotte MR, Johnson BE. A study of bite force, part 1: relationship to various physical characteristics. Angle Orthod 1995;65:367-72.

[26] Hidaka O, Iwasaki M, Saito M, Morimoto T. Influence of clenching intensity on bite force balance, occlusal contact area, and average bite pressure. J Dent Res 1999;78:1336-44.

[27] Sondang P, Kumagai H, Tanaka E, Ozaki H, Nikawa H, Tanne K, et al. Correlation between maximum bite force and craniofacial morphology of young adults in Indonesia. J Oral Rehabil 2003;30:1109-17.

[28] Sasaki K, Hannam AG, Wood WW. Relationships between the size, position, and angulation of human jaw muscles and unilateral first molar bite force. J Dent Res 1989;68:499-503.

[29] Erhardson S, Sheikholeslam A, Forsberg CM, Lockowandt P. Vertical forces developed by the jaw elevator muscles during unilateral maximal clenching and their distribution on teeth and condyles. Swed Dent J 1993;17:23-34.

[30] Bakke M, Stoltze K, Tuxen A. Variables related to masseter muscle function: a maximum R2 improvement analysis. Scand J Dent Res 1993;101:159-65.

[31] Shinogaya T, Bakke M, Thomsen CE, Vilmann A, Matsumoto M. Bite force and occlusal load in healthy young subjects-a methodological study. Eur J Prosthodont Restor Dent 2000;8:11-5.

[32] Wenneberg B, Kjellberg H, Kiliaridis S. Bite force and temporomandibular disorder in juvenile chronic arthritis. J Oral Rehabil 1995;22:633-41.

[33] Tortopidis D, Lyons MF, Baxendale RH. Bite force, endurance and masseter muscle fatigue in healthy edentulous subjects and those with TMD. J Oral Rehabil 1999;26:321-8.

[34] Ahlberg JP, Kovero OA, Hurmerinta KA, Zepa I, Nissinen MJ, Kononen MH. Maximal bite force and its association with signs and symptoms of TMD, occlusion, and body mass index in a cohort of young adults. Cranio 2003;21:248-52.

[35] Hansdottir R, Bakke M. Joint tenderness, jaw opening, chewing velocity, and bite force in patients with temporomandibular joint pain and matched healthy control subjects. J Orofac Pain 2004;18:108-13. 
[36] Ingervall B, Minder C. Correlation between maximum bite force and facial morphology in children. Angle Orthod 1997;67:415-22 discussion 23-4.

[37] Pepicelli A, Woods M, Briggs C. The mandibular muscles and their importance in orthodontics: a contemporary review. Am J Orthod Dentofac Orthop 2005;128:774-80.

[38] Rentes AM, Gaviao MB, Amaral JR. Bite force determination in children with primary dentition. J Oral Rehabil 2002;29:117480.

[39] Bonjardim LR, Gaviao MB, Pereira LJ, Castelo PM. Bite force determination in adolescents with and without temporomandibular dysfunction. J Oral Rehabil 2005;32:57783.

[40] Dean JS, Throckmorton GS, Ellis 3rd E, Sinn DP. A preliminary study of maximum voluntary bite force and jaw muscle efficiency in pre-orthognathic surgery patients. J Oral Maxillofac Surg 1992;50:1284-8.

[41] Bakke M, Holm B, Jensen BL, Michler L, Möller E. Unilateral, isometric bite force in 8-68-year-old women and men related to occlusal factors. Scand J Dent Res 1990;98:149-58.
[42] Miyaura K, Matsuka Y, Morita M, Yamashita A, Watanabe T. Comparison of biting forces in different age and sex groups: a study of biting efficiency with mobile and non-mobile teeth. J Oral Rehabil 1999;26:223-7.

[43] Shinogaya T, Bakke M, Thomsen CE, Vilmann A, Sodeyama A, Matsumoto M. Effects of ethnicity, gender and age on clenching force and load distribution. Clin Oral Investig 2001;5:63-8

[44] Kovero O, Hurmerinta K, Zepa I, Huggare J, Nissinen M, Kononen M. Maximal bite force and its associations with spinal posture and craniofacial morphology in young adults. Acta Odontol Scand 2002;60:365-9.

[45] Regalo SC, Santos CM, Vitti M, Regalo CA, de Vasconcelos PB, Mestriner Jr. W, et al. Evaluation of molar and incisor bite force in indigenous compared with white population in Brazil. Arch Oral Biol 2008;53:282-6.

[46] Linderholm H, Wennstrom A. Isometric bite force and its relation to general muscle forge and body build. Acta Odontol Scand 1970;28:679-89. 